\title{
Manasement of a patient with transverse mandibular dyssymmetry
}

\section{Benjamin DELVALLEZ, François GUYOMARD, Olivier SOREL}

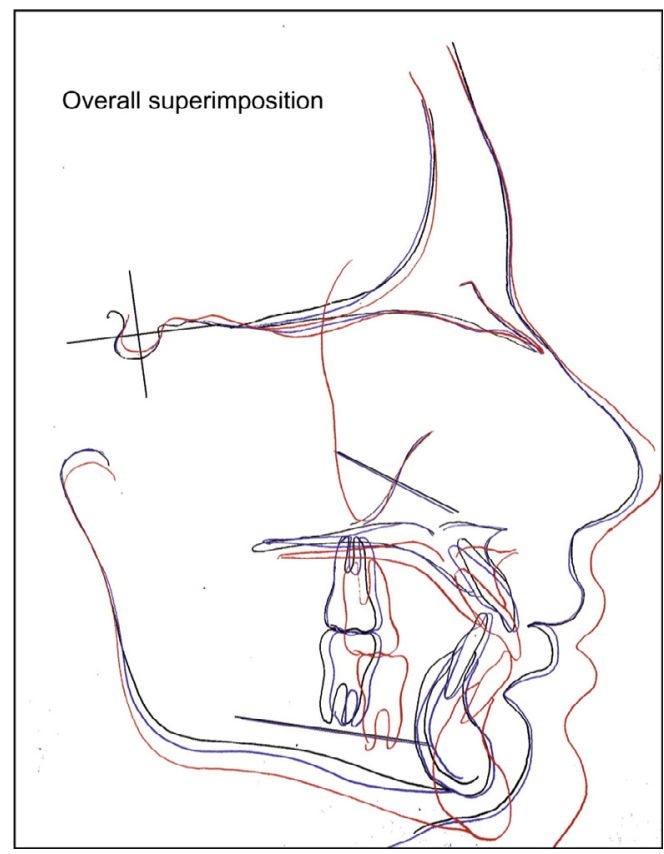

INTRODUCTION

Cases of dyssymmetries of the basal bone and/or of the dentoalveolar arches are complicated to manage. Orthognathic surgery is often a necessary means for achieving treatment objectives.
This report presents the management of a case of a skeletal Class II associated with a mandibular dyssymmetry and a mild otomandibular syndrome.
Address for correspondence:

B. Delvallez

31D rue Vaneau, 35000 Rennes

delvallez.ben@voila.fr
Article received: 02:2013.

Accepted for publication: 03:2013. 


\section{ETIOLOGY AND DIAGNOSIS}

A young 16 year old patient named Dorian was referred to us in November, 2006 with delayed dental eruption, especially of the lower canines.

He was diagnosed with:

- Facial: a right-left facial asymmetry with a protruding left ear, and a deviation of the chin (Fig. 1). His forced smile hardly shows his upper incisors. His profile shows a slightly retruded mandible and the comparative size of the lower third of the face is diminished, the nasolabial angle is slightly closed and the cervical-mental distance is diminished.
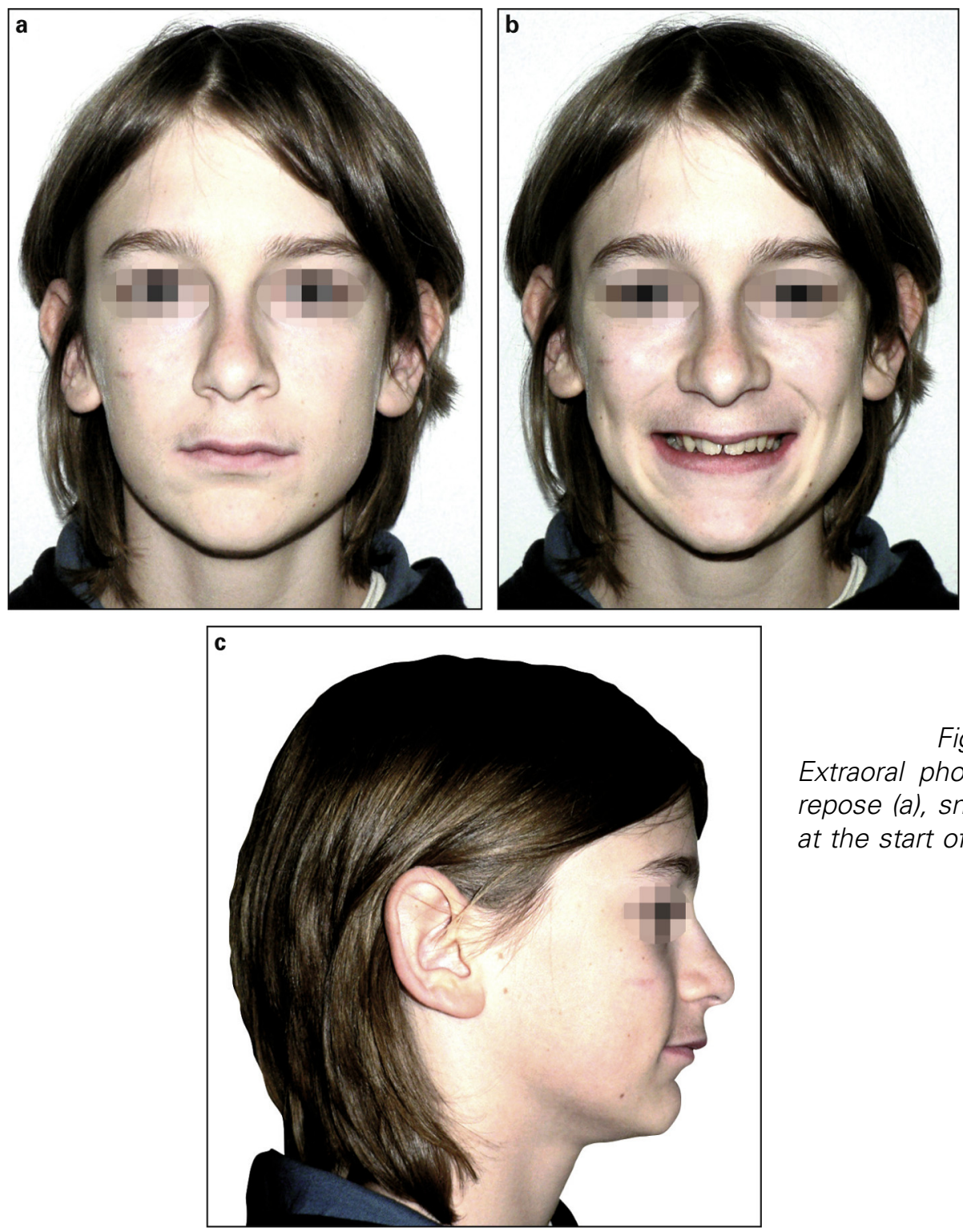

Figure 1

Extraoral photographs face at repose (a), smile (b), profile (c) at the start of treatment. 

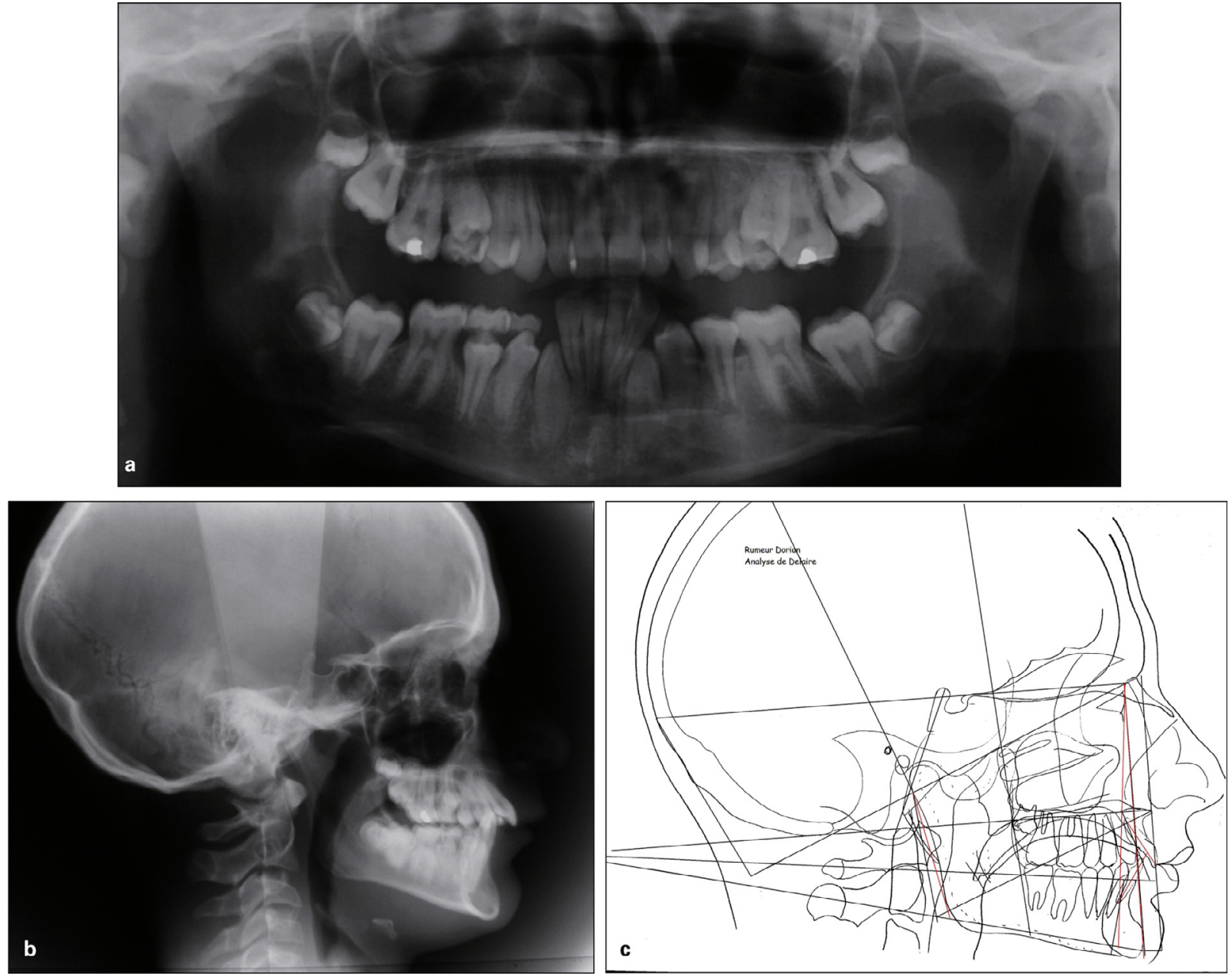

Figure 2

Initial panoramic xray (a), lateral cephalometric xray (b), Delaire analysis on xray 10 months after the start of treatment.

- Skeletal: a narrow maxilla, a weak skeletal class II with a slightly receded chin (ANB $4^{\circ}$ ), a mandibular asymmetry and a reduced anterior vertical facial height (SN/GoGn $16^{\circ}$.

- Dentoalveolar: lingualized maxillary and mandibular teeth, overall retrusion of the mandibular arch and a maxillary protrusion (I/Na $6 \mathrm{~mm})$.
- Dental relationships: an Angle class II with right subdivision of $2 \mathrm{~mm}$, an incisal overjet of $7 \mathrm{~mm}$, lower incisors completely hidden and severe dentomaxillary discrepancy. The interincisal midlines are not deviated. But the mandibular interincisal midline does not align with the mandibular basal midline. The patient also has malformed maxillary first molars. 


\section{TREATMENT OBJECTIVES}

The solution to this bone disorder will be maxillary and mandibular orthognathic surgery. A Lefort 1 lowering of the maxilla, a slight advancement of the body of the mandible and a mandibular derotation with saggital osteotomies of the ascending rami. A significant dentoalveolar correction will be required in order to establish alignment between the mandibular interincisal midline and the mandibular basal bone.

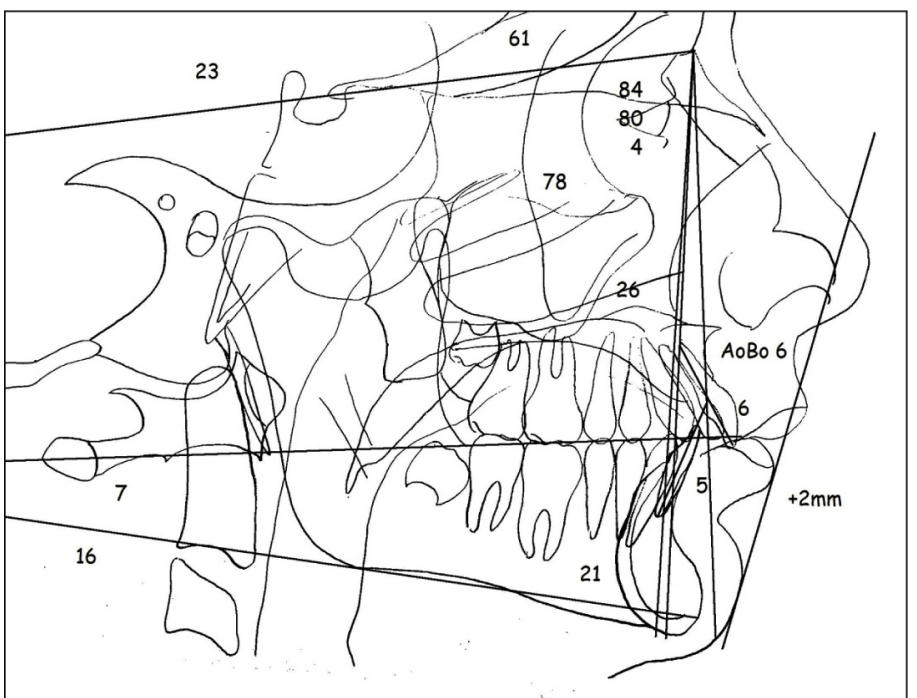

Figure 3

Initial Steiner analysis on lateral cephalometric xray 10 months after the start of treatment.

Figure 4

Facial AP xray.
The dentoalveolar problem will be resolved by alveolar expansion and not by extractions even though there were long and lively debates before and during treatment. The choice to not extract was motivated by the possibility of increasing the width of the alveolus and inclining the mandibular incisors labially. An intrusion of the incisors and canines should be performed but the incisor overjet will

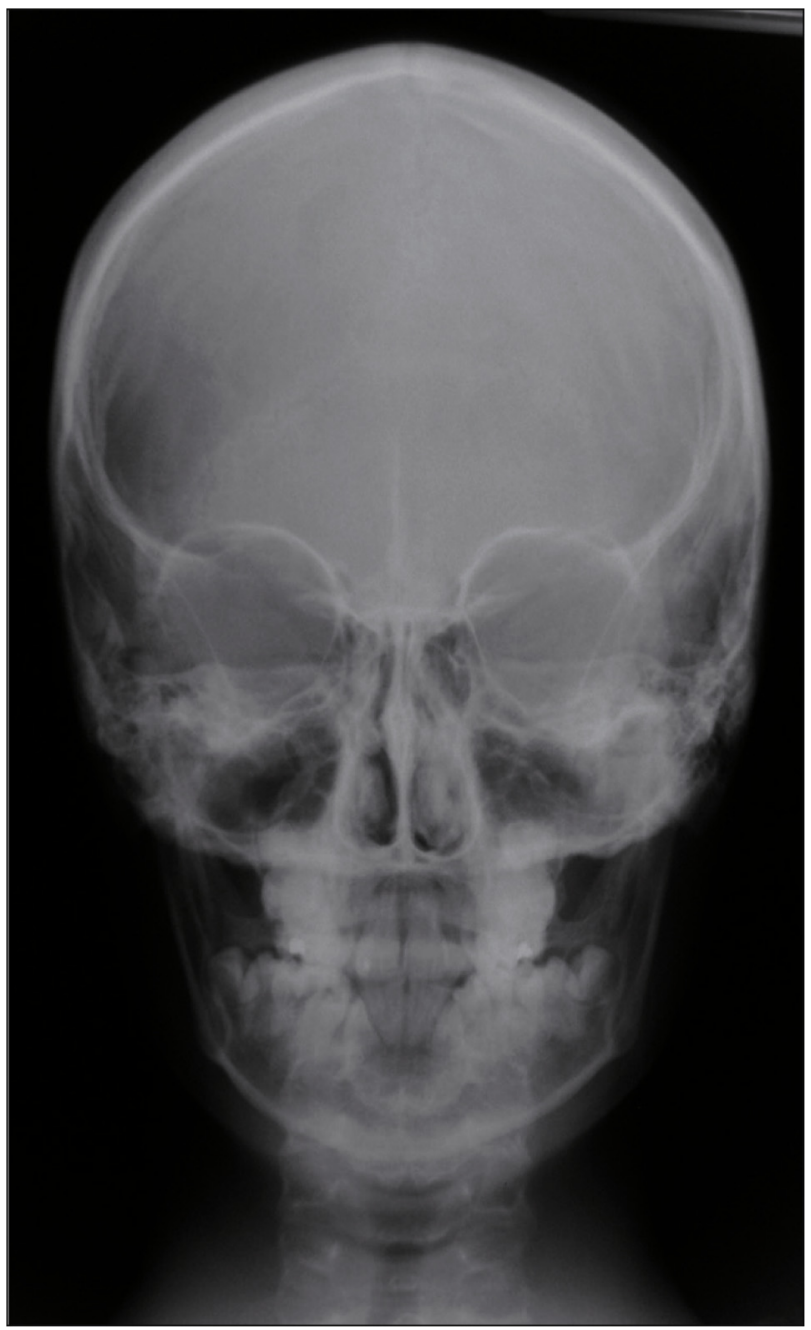



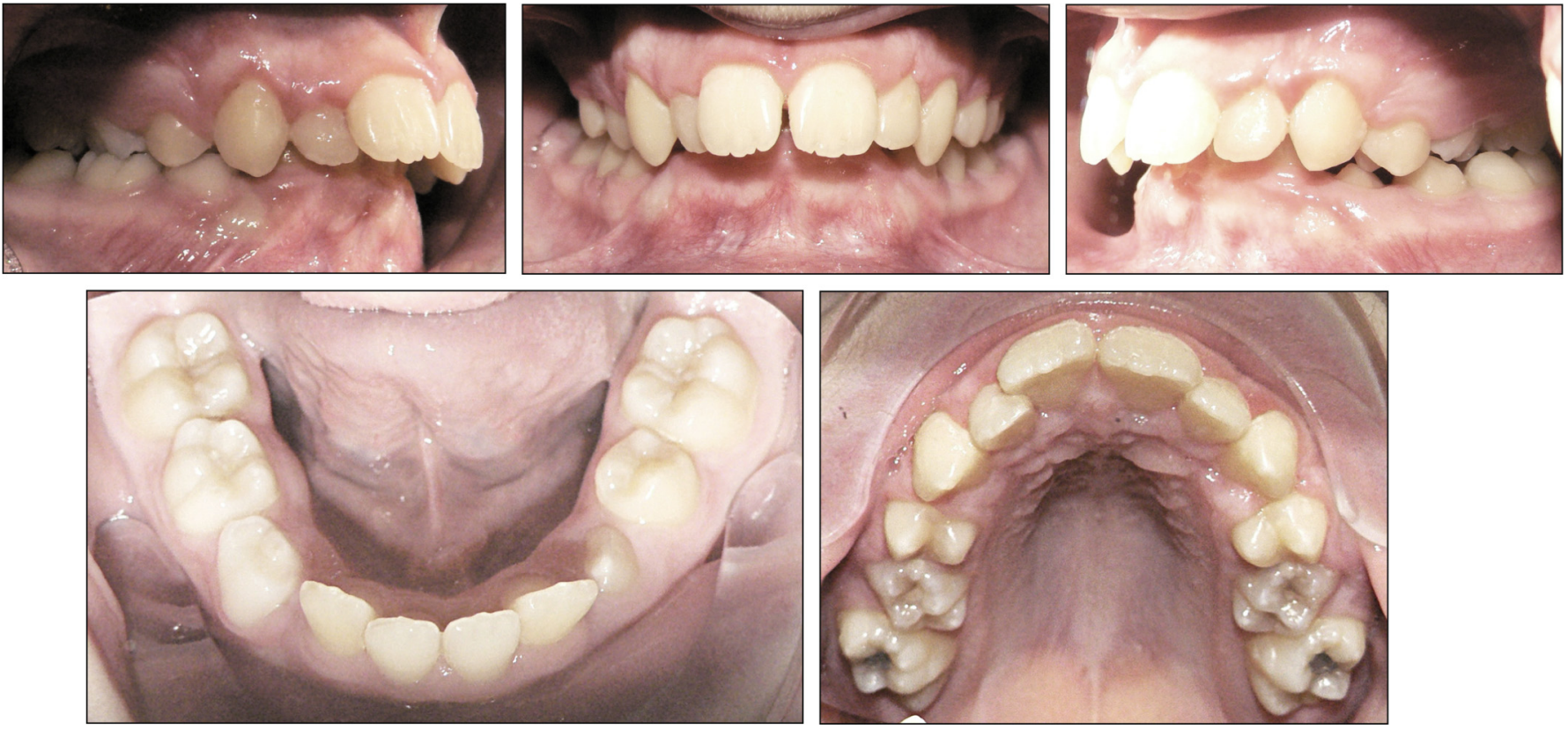

Figure 5

Initial intraoral photographs.
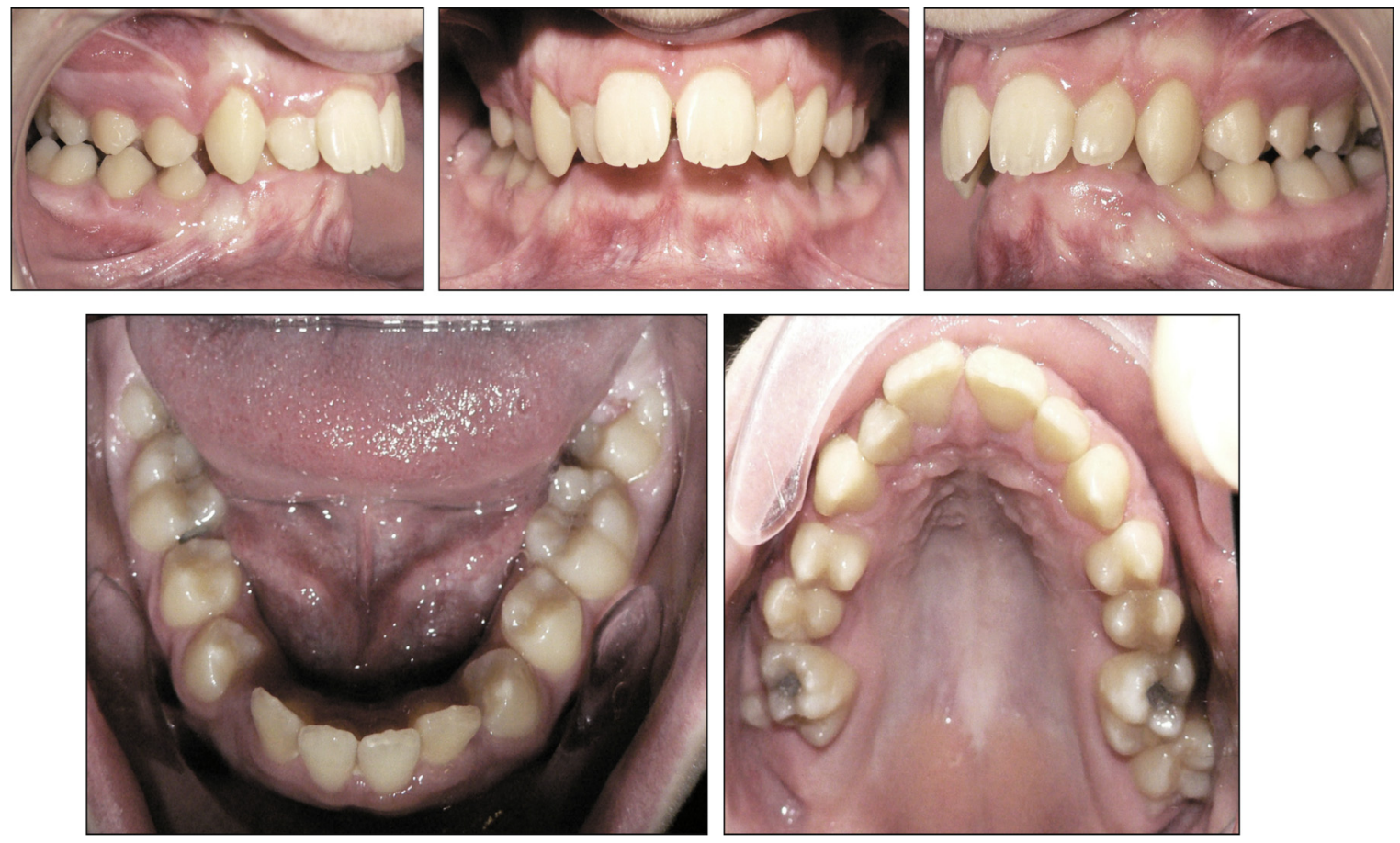

$\varangle$

$<$

Figure 6

Initial intraoral photographs at the start of treatment. 
largely be resolved by the orthognathic surgery.

The incisor overjet should be reduced because it is far greater than the necessary mandibular advancement.

\section{TREATMENT STEPS}

Treatment was started once all the permanent teeth had erupted, or 10 months after the orthognathic evaluation (October 2007).

Alignment and maxillary leveling were achieved after 8 months of treatment. Mandibular alignment as well as the traction of 33 were successfully treated two years after the beginning of therapy. Slow mandibular and maxillary alveolar expansion was accomplished (1 $1 / 2$ years).

Mandibular leveling was not completely achieved in order to obtain a post-surgical bilateral posterior opening with the objective of extruding the posterior sectors to resolve the vertical discrepancy.

It took a long time to establish the coordination of the arches. The presurgical treatment lasted for 3 years (November 2010). The post-surgical treatment lasted for 6 months (end of June 2011).

We observed a worsening of the profile during the pre-surgical preparation (Fig. 8). The smile remained unchanged. The smile will be improved by lowering the maxillary.

An analysis of the lateral cephalometric xray (Fig. 9) shows a labial inclination of the maxillary incisors of

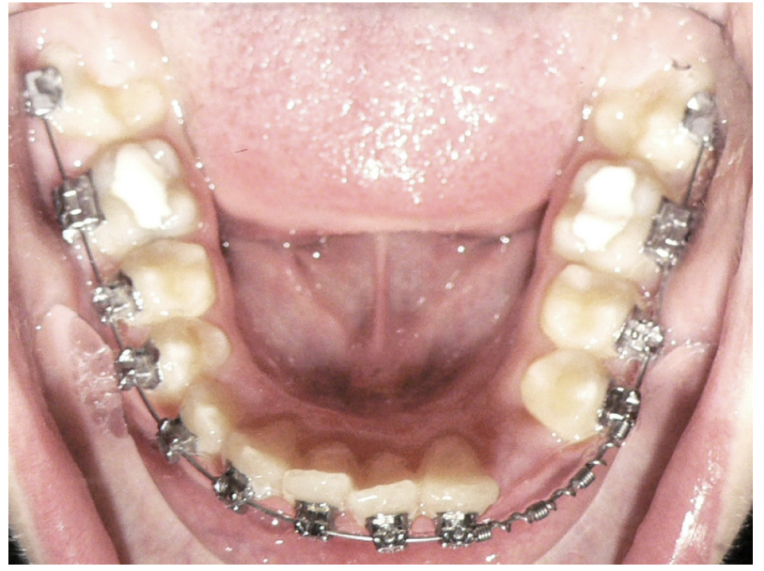

Figure 7

Intraoral photograph at the start of traction on 33 .

$10^{\circ}\left(\mathrm{I} / \mathrm{Na} 36^{\circ}\right)$ and of the mandibular incisor of $6^{\circ}\left(\mathrm{i} / \mathrm{Na} 27^{\circ}\right)$.

A superimposition clearly demonstrates the movements that were achieved (Fig. 10). A partial correction of the overjet was not established by a true intrusion of the mandibular incisors but rather by an extrusion of the maxillary and mandibular molars and a labial inclination of the maxillary and mandibular incisors.

The AP head film clearly shows the alignment of the mandibular incisors with the mandibular basal midline (Fig. 11).

Surgery was performed to lower the maxilla with a clockwise rotation and advancement of the body of the mandible more to the right than to the left. The surgeon left a minor posterior open bite. Treatment was resumed 6 months after the bi-maxillary orthognathic surgery.

The surgeon did not achieve as great a mandibular derotation as we 

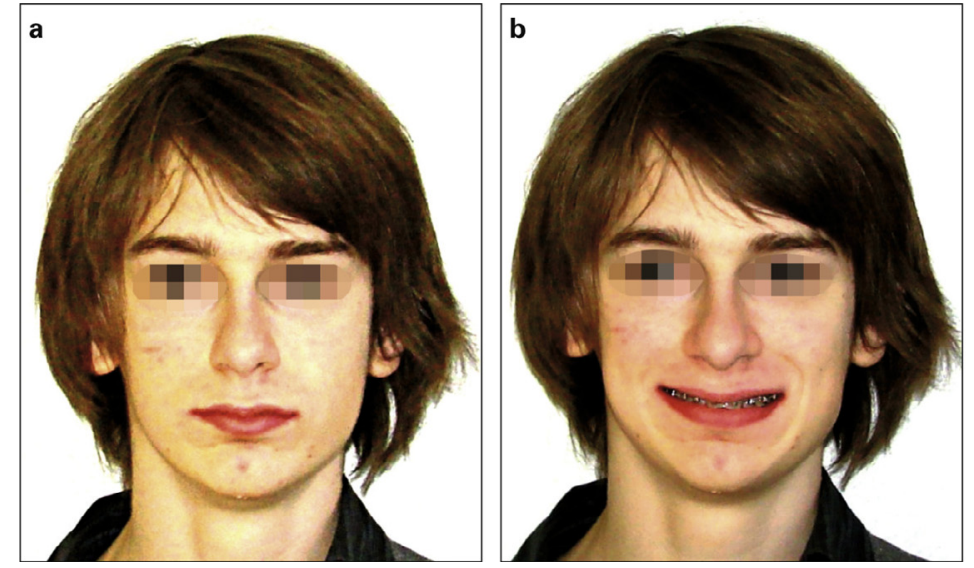

Figure 8

Pre-surgical facial photographs, face at repose (a) smile (b), and profile (c).
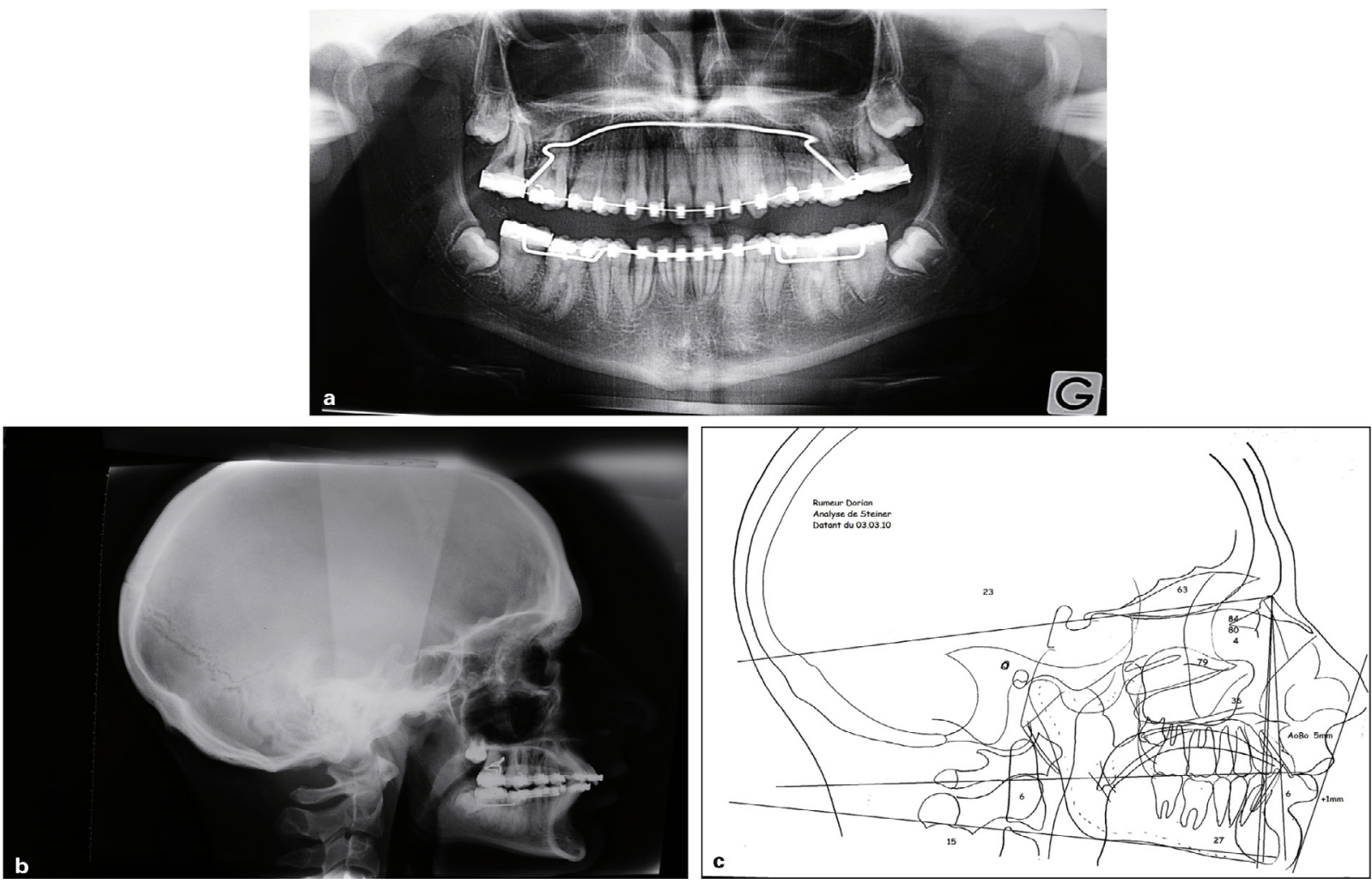

Figure 9

Pre-surgical panoramic xray (a), pre-surgical lateral cephalometric xray (b), and pre-surgical Steiner analysis (c). 

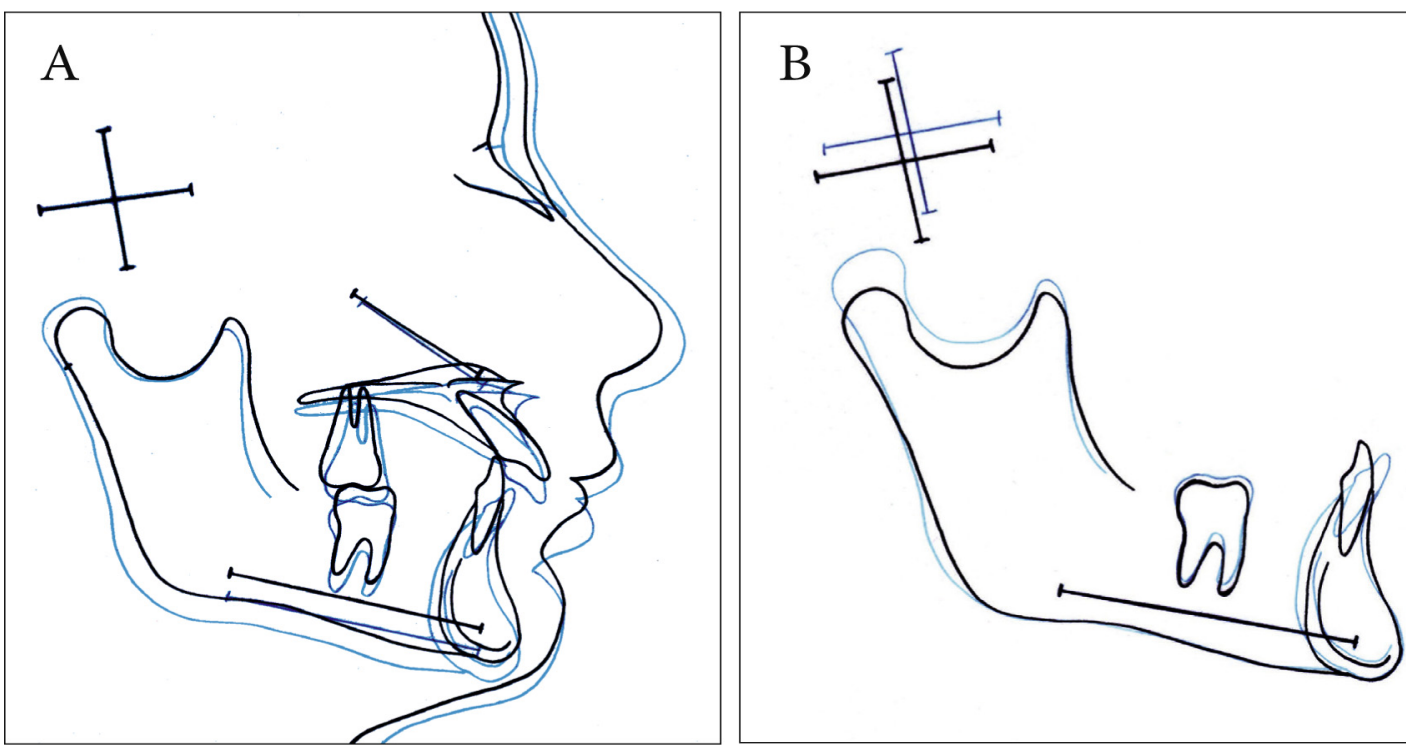

Figure 10

Pre-surgical superimposition according to the LVD method: Overall $A$ and mandibular $B$.
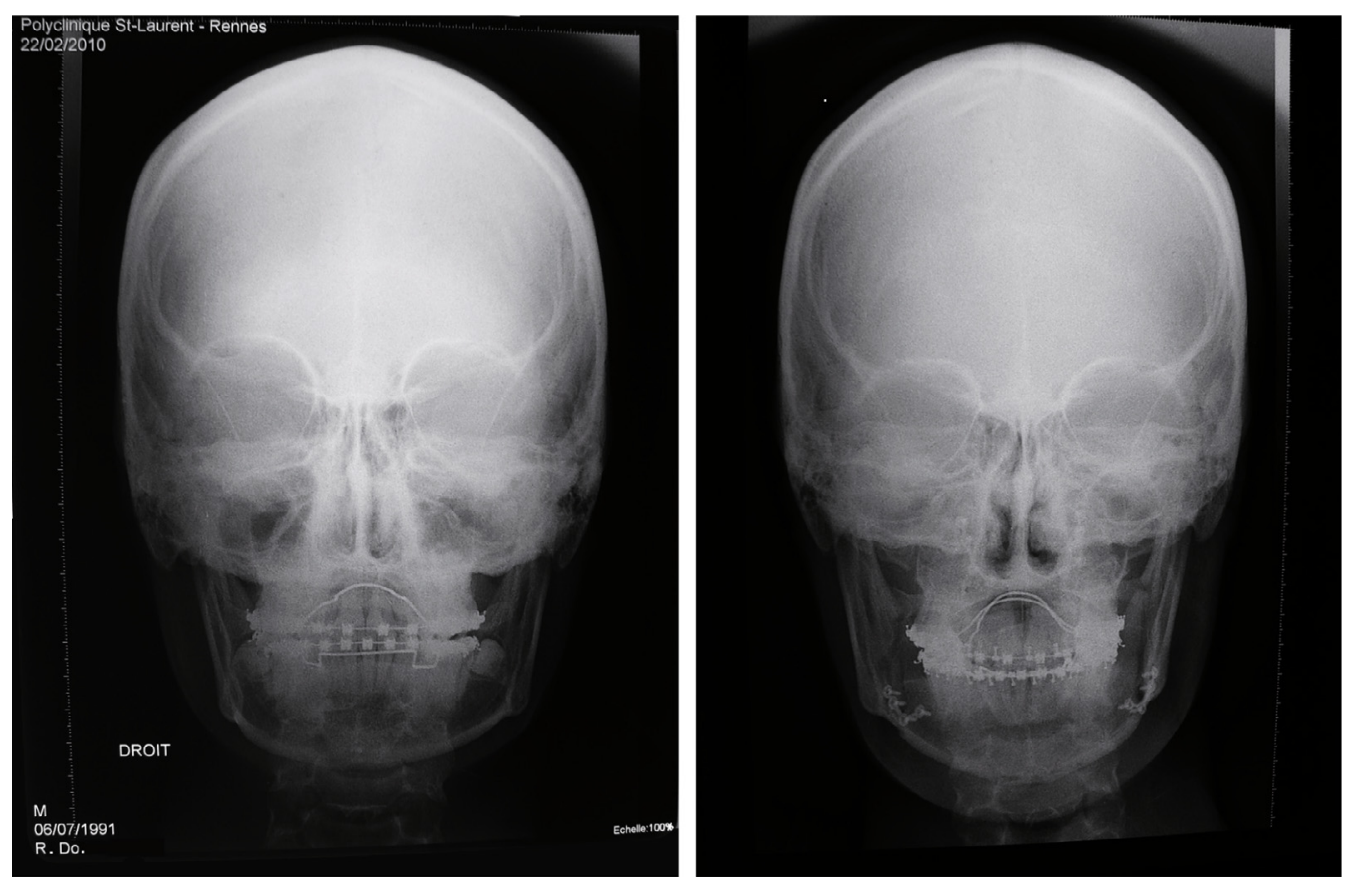

Figure 11

Pre- and post-surgical facial AP xrays. 

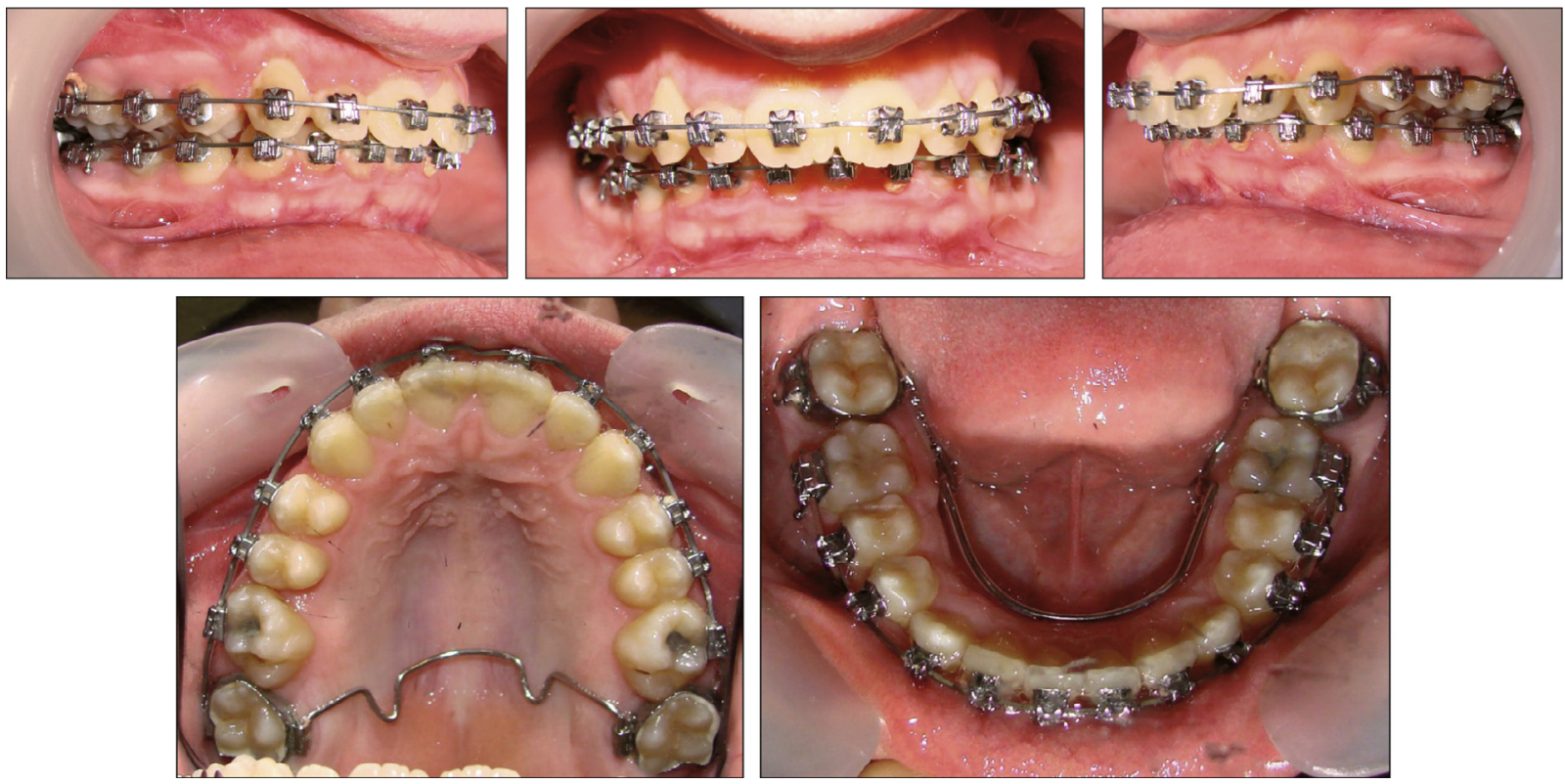

Figure 12

Pre-surgical intraoral photographs.
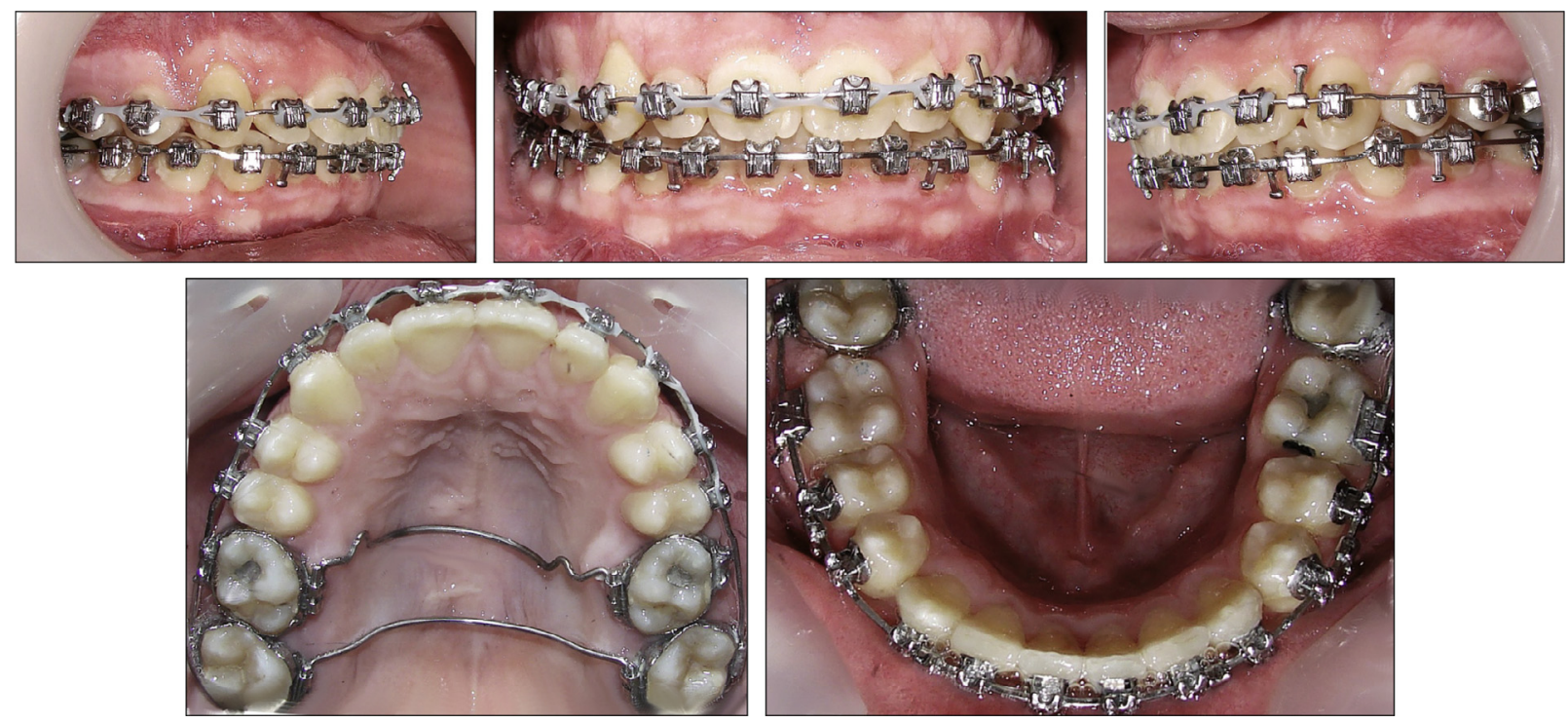

Figure 13

Post-surgical intraoral photographs. 

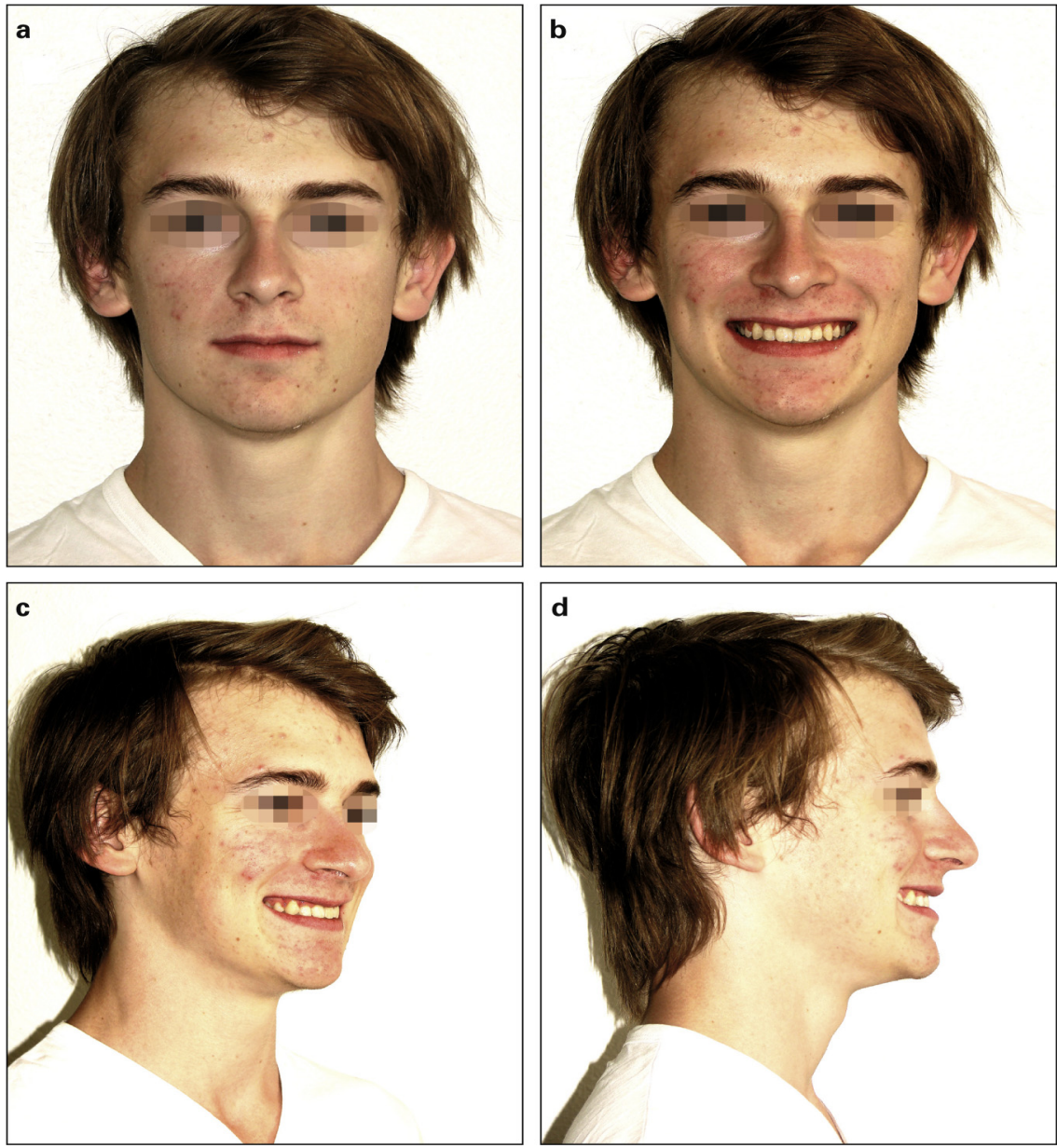

Figure 14

Facial photographs face at repose (a), Smile (b), three-quarter facial smile (c), and profile (d).

had expected (Fig. 15), because he decided that he would have had to move the facial chin too far to the patient's left.

The finishing touches consisted of reducing the $3 \mathrm{~mm}$ post-surgical intercisal midline discrepancy and achieving posterior occlusion.

We can see in Figure 14 that the teeth appear in the smile, the vertical dimension of the lower third of the face has improved and the profile is straighter.

A post-surgical Steiner Analysis shows an improvement of the ANB $\left(2^{\circ}\right)$, a surgical reduction of the labial inclination of the maxillary incisors of $6^{\circ}\left(\mathrm{I} / \mathrm{Na} 30^{\circ}\right)$ (Fig. 15). The inclination of the mandibular incisors is almost identical. 


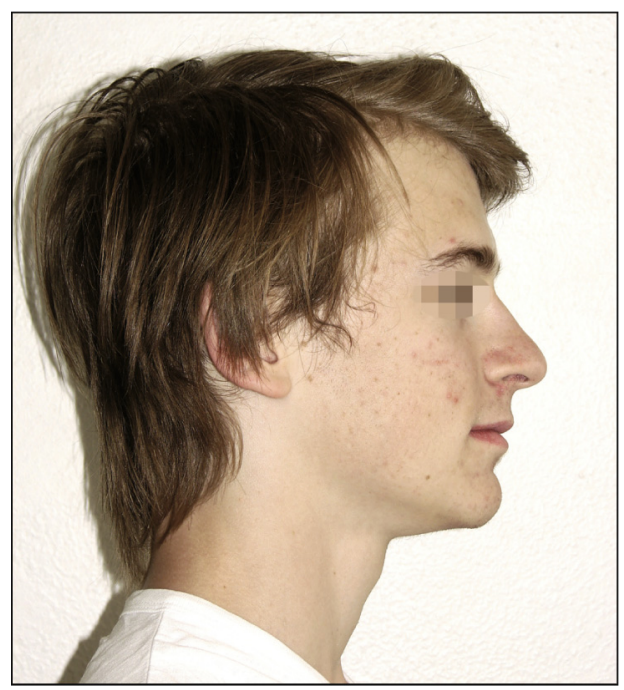

Figure 15

Facial profile at the end of treatment.
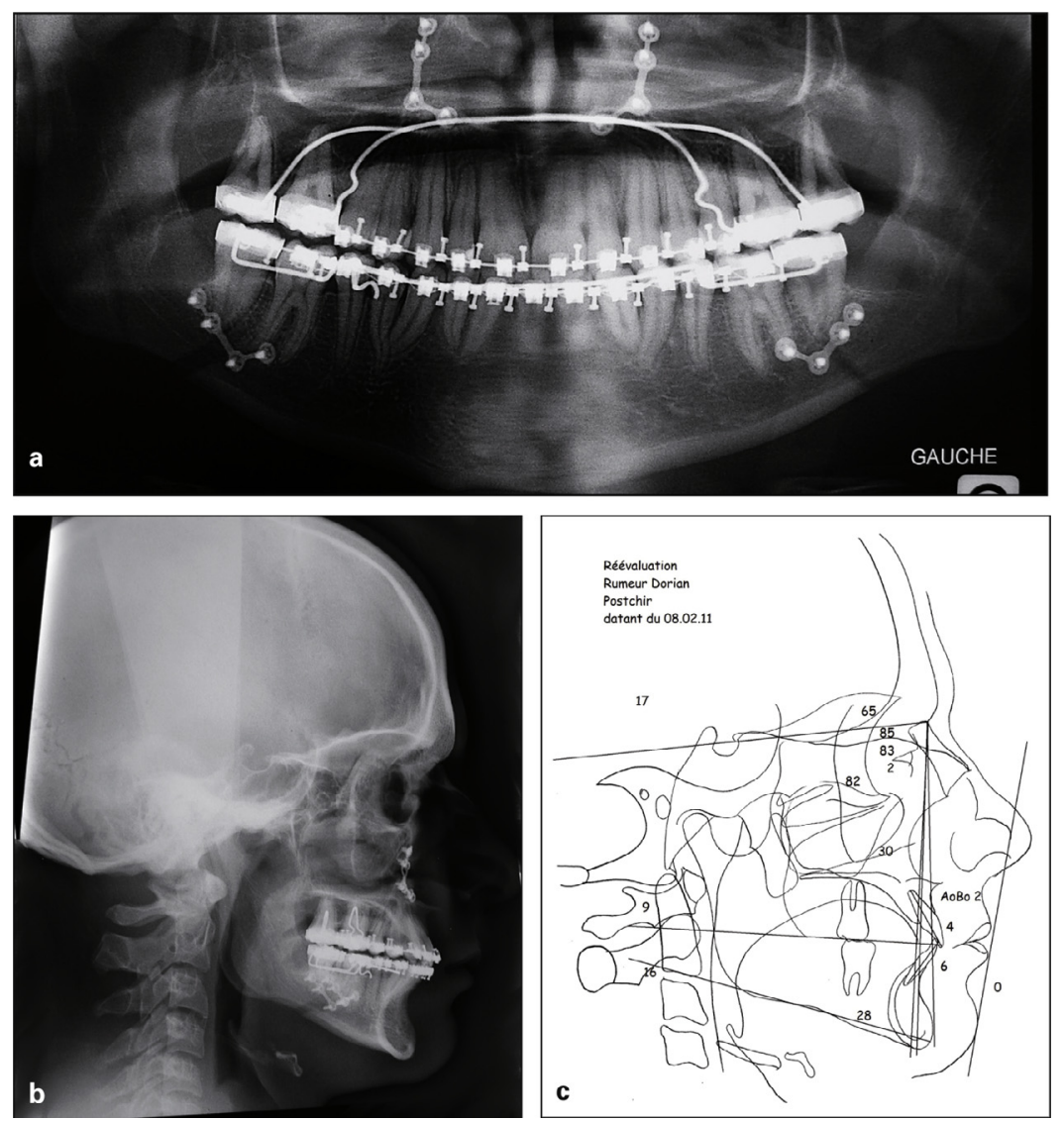

Figure 16

Panoramic xray (a), lateral cephalometic xray (b) Steiner analysis (c) post-surgical. 


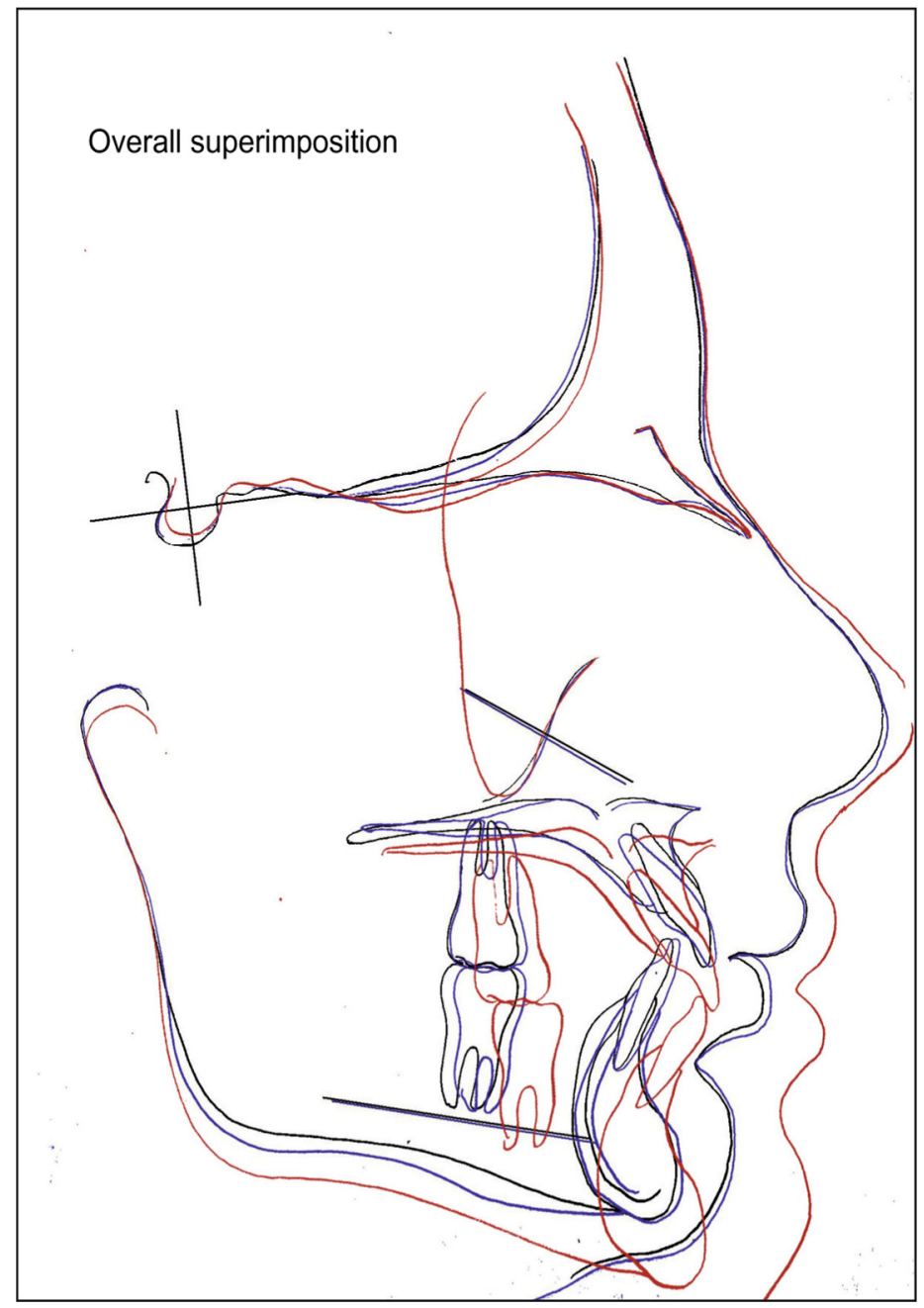

Figure 17

Overall superimposition at the end of treatment: initial tracing in black, pre-surgical tracing in blue and post-surgical tracing in red.

DISCUSSION

The stability of the treatment always has to be assessed. In fact, increases in intercanine and intermolar distances were required. There is still a mesiolingual rotation of 36 but fortunately this allows for efficient interlocking of 36 and 26 (since the coronal shape of 26 is very unusual).
There is still a slight discrepancy of the interincisal midlines of $1.5 \mathrm{~mm}$. The diastema between 23 and 22 has been filled by two esthetic restorations, on the mesial of 22 and on the distal of 23 . The inclination of the maxillary canines is different $(23$ is more corono-buccally inclined) with an 

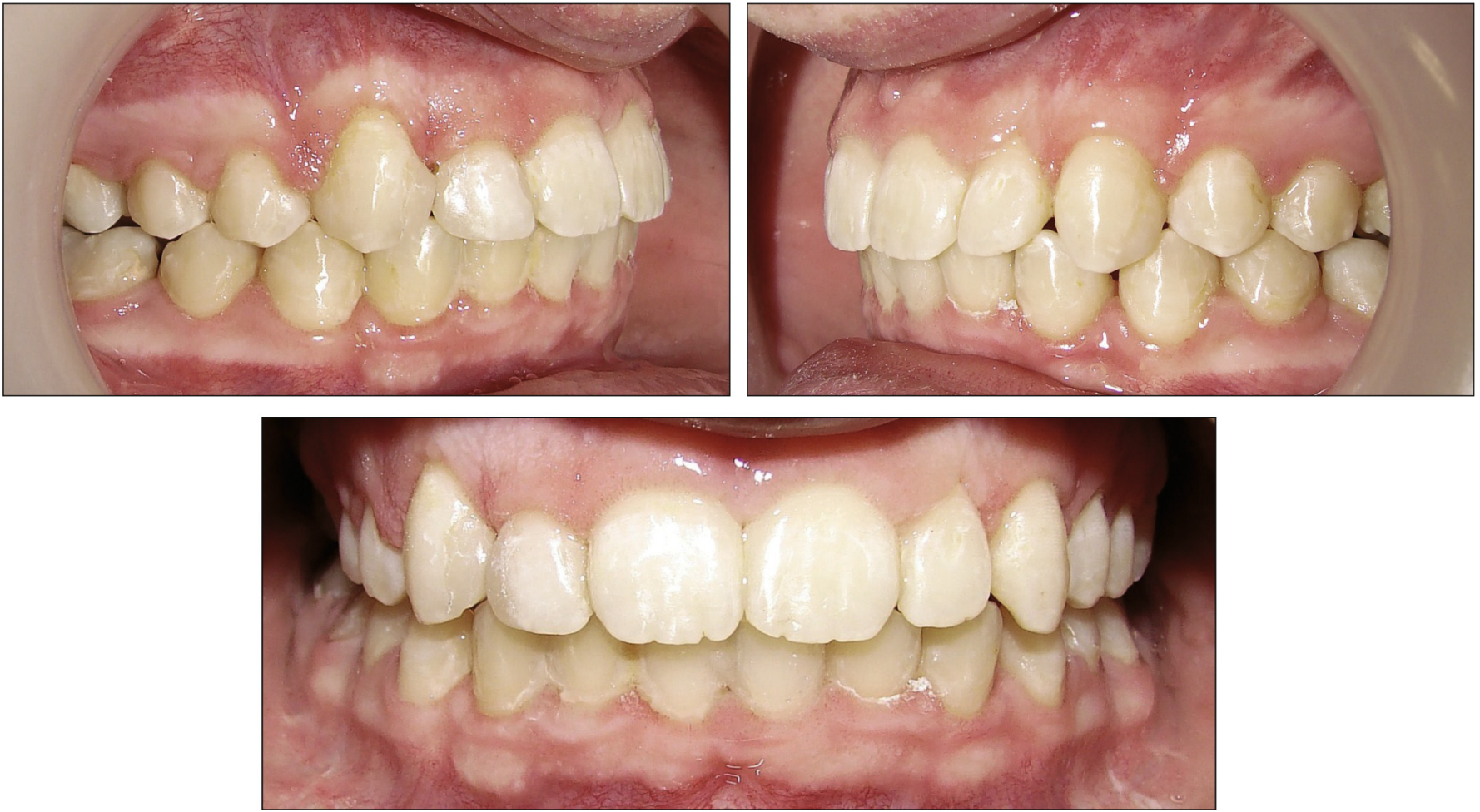

Figure 18

Post-treatment introral photographs.
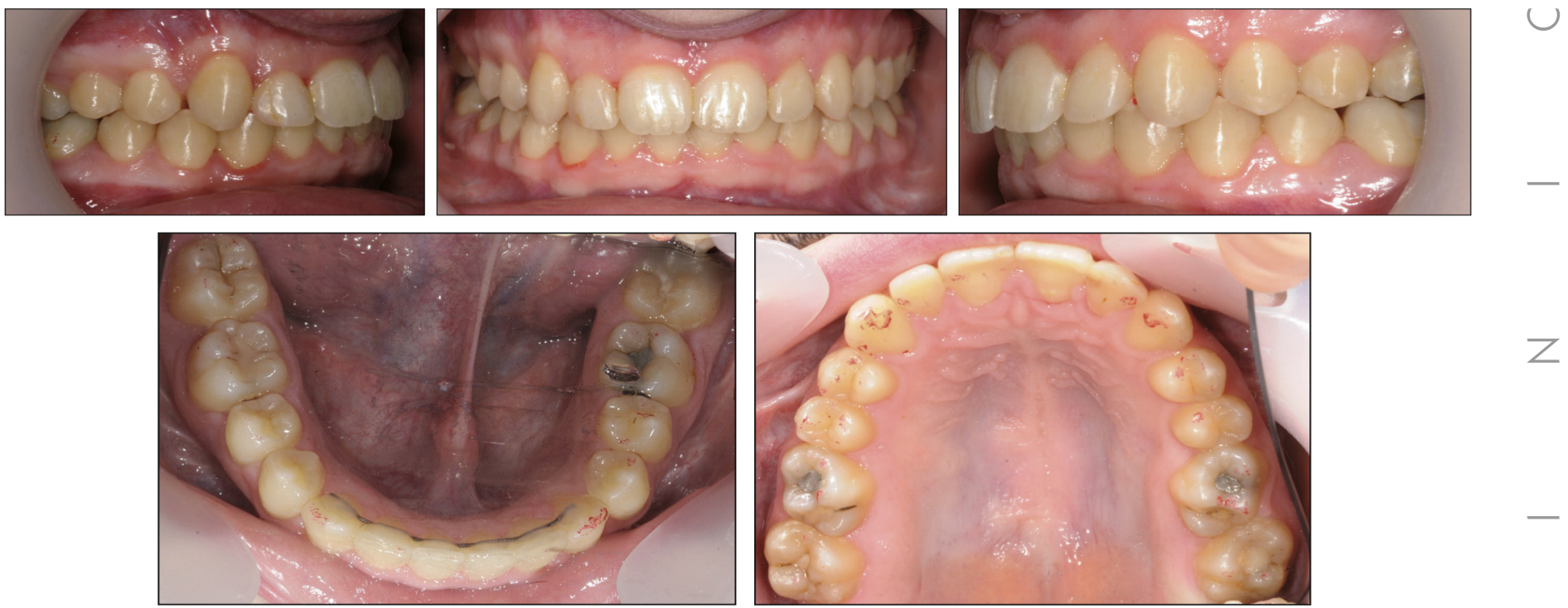

Figure 19

Intraoral photographs 1 and 1/2 years after treatment. 


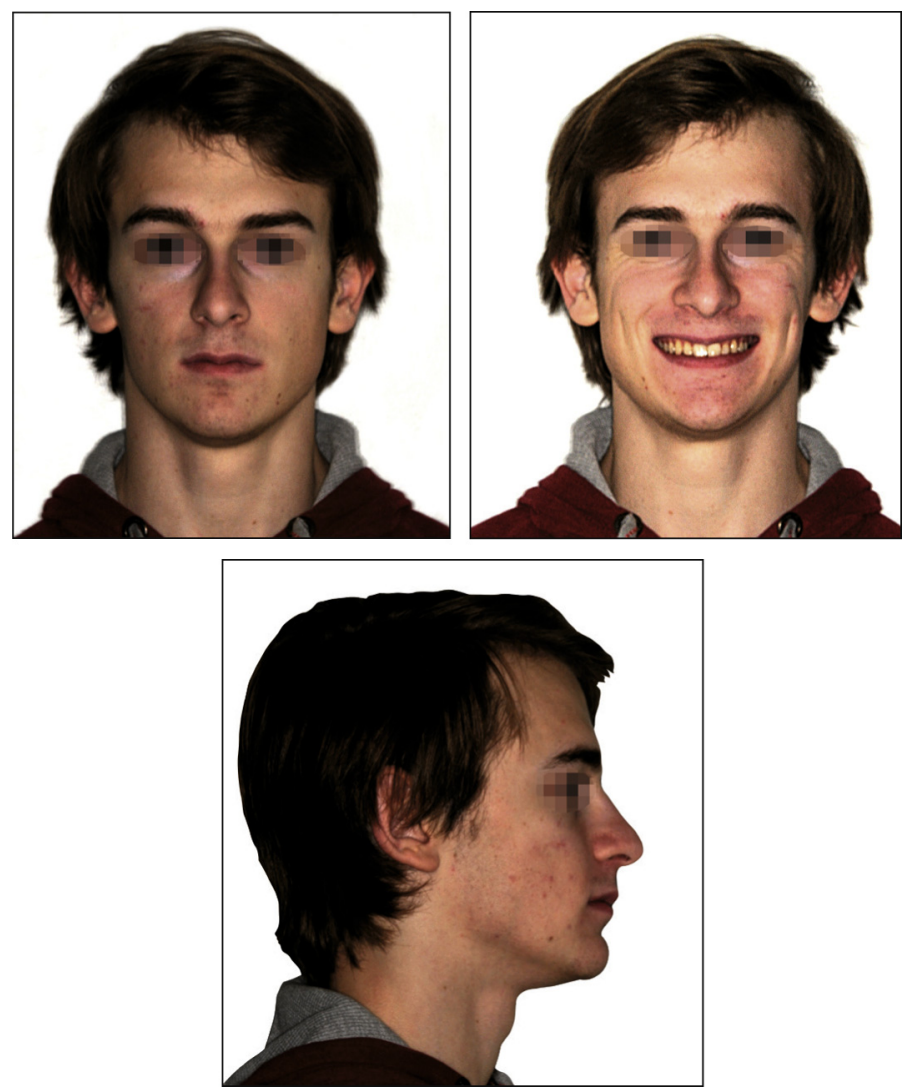

Figure 20

Facial photographs 1 and 1/2 years after the end of treatment.

AFMP slightly greater than on the left. Therefore, we performed a slight coronoplasty on the palatal face of 13. There is left and right canine guidance. Due to the length of presurgical treatment (that exhausted the motivation of our 20 year old patient) and the appearance of white spots (synonymous with poor oral hygiene), he asked us to curtail the finishing touches because he was concerned

\section{CONCLUSION}

Because the management of the therapy was tridimensional, we had to about whether the risk-benefit relationship was a positive one. In spite of this, the esthetics, the Class 1 static occlusion of the right and left molars and canines and the dynamic occlusion are entirely correct. The vestibular periodontium of the mandibular incisors does not seem to be weakened or harmed by the treatment (verification by probing, radiography and palpation). make casts of several models and assemble three articulated montages 
in order to situate all the components in the three dimensions of space. The communication and team work involving the motivated patient, the maxillofacial surgeon, the dental consultants and the students in charge of the patient, were the key to the success of the active treatment. Practitioners will have to carefully monitor the stability of the treatment. We recently took photographs $1 \frac{1}{2}$ years after the end of treatment (January 2012) and the stability seems correct (Fig. 19, 20).

Special thanks to Dr. Le Strat and to Professor Guyomard.

\section{REFERENCES FOR CONSULTATION}

1. Casteigt J, Faure J, Labarrère H, Treil J. Symbiose chirurgico-occlusoorthodontique dans les dysmorphies maxillofaciales. EMC 23-499-A-10, 2006, Elsevier SAS.

2. Cheong YW, Lo LJ. Facial asymmetry: etiology, evaluation, and management. Chang Gung Med J 2011 34(4):341-51.

3. Garcia C, La chirurgie orthognathique du futur. Orthod Fr 2008;79:67-77.

4. Dahan J, Troubles d'attitudes mandibulaires. 23-472-A-10, 2002, Editions Scientifiques et Médicales Elsevier SAS.

5. Guyot L, Brignol L, Thiery G, Cheynet F, Chossegros C, Gola R. Traitement chirurgical des rétromandibulies par avancée mandibulaire par cale cartilagineuse rétrocondylienne. EMC 23-499-A-11 Odontologie/Orthopédie 2007 Elsevier Masson SAS.

6. Richter M, Mossaz C, Laurent F, Goudot P. Chirurgie correctrice des dysmorphies maxillomandibulaires. Insuffisances et excès sagittaux associés à une hauteur faciale normale. EMC 22-066-E-20, 2000. Elsevier SAS.

7. Zhang Y, Che B, Ni Y, Zhang H, Pan Y, Wang L, Ma J. Three-dimensional condylar positions and forms associated with different anteroposterior skeletal patterns and facial asymmetry in Chinese adolescents. Acta Odontol Scand, 2013 ; DOI : 10.3109/ 00016357.2012 .757359 